\title{
HEALTHCARE - WHERE TO FROM HERE?
}

\author{
DS Briggs AM, Editor in Chief
}

In writing an editorial it is difficult to ignore the impact and ramifications of addressing the Covid Pandemic. In Australia, there is emerging political and media signals that are saying we must start to move on and get people back to work and living normally. At the same time our health bureaucracies are pointing to higher vaccination rates, new variants, the need for 'booster shots' and continued reticence in some about opening state and national borders.

At the same time, we are seeing 'degrees of anxieties' about the continued need for protection and surety of care, together with protests about mandated vaccinations or just plain antagonism about lost freedoms and being 'rewarded' for compliance. In rural areas we are dealing with substantial flooding at harvest time, as well. All these tensions exist side by side in a country that comparatively has done relatively well.

We have had Royal Commissions into aspects of the Australian health systems, a senate Inquiry into current state and former Government reforms to outer metropolitan, rural and regional GP services and their impact on GPs and in the State of NSW an ongoing Upper House Inquiry into rural health services. Closure of borders to international students have seen reactive contraction of courses and staffing at universities at a time when the health workforce is in short supply. We also discovered that the previously available international students were also an important part of our general workforce. Their imminent return will be welcomed.

The federated system in Australia of differing levels of government responsibility for healthcare seems to be haphazard but remains resilient to change and reform. One exception to the rule appears to be the networked and collaborative Tropical Australian Academic Research Centre in a presentation by Emeritus Professor lan Wronski AO, Chair of that organisation, that seems to be able to align research education and health planning and provision together in a cooperative geographic fashion, so much more than others have been able. The centre is located in the north of Queensland and the presentation was at the recent SHAPE Symposium.

In contrast, in Thailand in a National health system, the primary healthcare system is being separated out to become more of local government and provincial responsibility while the Health Ministry retains responsibility for other health services. An area health board at provincial level is being considered to ensure the systems are connected and collaborate.

At another conference, in Hong Kong, The CPCE Conference, our Colleague, Professor Peter Yuen, questioned what might happen to the health system, post pandemic. His data suggests that the Hong Kong health system was already under stress pre-pandemic and that past reform of that system have failed. He questions the use of public money in that system. His data suggests an overreliance on institutional and residential care for the elderly, higher than Australia but not much more than a percentage point. He emphasises that end of life care in Hong Kong is predominantly in hospitals and institutions, unlike the predominance of home and community care in other comparable countries. Professor Yuen suggests that the dominant use of inpatient hospital care exists where the evidence is that $50 \%$ of all public hospital conditions in Hong Kong 'were ambulatory care sensitive' and could be treated on an outpatient treatment basis to provide substantial cost savings. Some important thinking and challenges for us all.

The pandemic, concepts of innovation, advancing technology, big data and the internet of things are also presenting us with new opportunities to address these challenges to address the system inertia and, deal with the 


\section{References}

'strife of interests', as Sidney Sax once said and improve healthcare.

There is much for us to do within existing systems if government and bureaucracy and the other structural interests, stepped back, allowed us space, and gave permission for cross sectorial, collaborative, and networked health service delivery. A lot to be done, best wishes to you all in your future professional endeavors in 2022.

DS Briggs AM

Editor in Chief
1. Professor Ian Wronski OA Deputy Vice Chancellor of James Cook University and interim Chair of the Tropical Australian Academic Health Centre - 'Integrating health research, research education and health service delivery to address the priority health needs of northern Australia'. Presented at the SHAPE INTERNATIONAL SYMPOSIUM 2021 "Shaping the future for health management education and research in a time of flux and uncertainty" July 2021.

2. Professor Peter P. Yuen, PhD. Dean College of Professional \& Continuing Education. The Hong Kong Polytechnic University. 'What Should Happen to our Healthcare and Long-Term Care Systems After the Pandemic? Back to the Old Normal? Should we have a New Normal?' CPCE Health Conference 2021. The Hong Kong Polytechnic University. September 2021. 